\title{
Postmenopausal cognitive changes and androgen levels in the context of apolipoprotein E polymorphism
}

Iwona Bojar ${ }^{1}$, Jarosław Pinkas ${ }^{2}$, Mariusz Gujski ${ }^{3}$, Alfred Owoc ${ }^{4}$, Dorota Raczkiewicz ${ }^{5}$, Kasia Gustaw-Rothenberg6,7

1Department for Women Health, Institute of Rural Health, Lublin, Poland
2School of Public Health, Center of Postgraduate Medical Education, Warsaw, Poland
${ }^{3}$ Department of Prevention of Environmental Hazards and Allergology,
Medical University of Warsaw, Warsaw, Poland
${ }^{4}$ Center for Public Health and Health Promotion, Institute of Rural Health, Lublin,
Poland
5Institute of Statistics and Demography, Warsaw School of Economics, Warsaw,
Poland
${ }^{6}$ Lou Ruvo Brain Wellness Center, Neurological Institute, The Cleveland Clinic
Foundation, Cleveland, OH, USA
${ }^{7}$ Department of Neurodegenerative Diseases, Institute of Rural Health, Lublin, Poland

Submitted: 6 June 2016

Accepted: 25 July 2016

Arch Med Sci 2017; 13, 5: 1148-1159

DOI: 10.5114/aoms.2016.62869

Copyright $\odot 2016$ Termedia \& Banach

\section{Abstract}

Introduction: The focus of this study was to assess cognitive functions in relation to androgens and specifically testosterone and dehydroepiandrosterone in postmenopausal women as well as the correlation between cognitive functions and these two androgens according to polymorphism of the apolipoprotein E gene (APOE).

Material and methods: A group of 402 women was recruited to the study (minimum 2 years after the last menstruation, follicle-stimulating hormone (FSH) more than $30 \mathrm{U} / \mathrm{ml}$ and no dementia signs on Montreal Cognitive Assessment). The computerized battery of the Central Nervous System Vital Signs test was used to diagnose cognitive functions. APOE genotyping was performed by multiplex polymerase chain reaction (PCR). Testosterone (TTE) and dehydroepiandrosterone (DHEA) in the blood serum were assessed for further statistical correlations analysis.

Results: In the group of postmenopausal women, higher testosterone concentration was associated with lower scores for Neurocognition Index $(\mathrm{NCl})$ $(p=0.028)$, memory $(p=0.008)$ and psychomotor speed $(p<0.001)$. Presence of at least one APOE $\varepsilon 4$ allele potentiated testosterone's negative influence on cognitive functions $(p<0.05)$. Woman with a high normal level of DHEA scored significantly better in verbal $(p=0.027)$ and visual memory $(p<0.001)$ than other participants. APOE polymorphism did not modify the relationship between DHEA concentration and scores for cognitive functions. Conclusions: Hormonal balance variations after menopause may influence brain processes concerned with cognition, especially memory and psychomotor speed. The observed effects may be related to androgens' influence on higher cortical functions in the changed hormonal dynamics of the postmenopausal period.

Key words: cognitive functions, testosterone, dehydroepiandrosterone, menopause, apolipoprotein $\mathrm{E}$.

\author{
Corresponding author: \\ Iwona Bojar \\ Department for \\ Women Health \\ Institute of Rural Health \\ 2 Jaczewskiego St \\ 20-090 Lublin, Poland \\ Phone: +48 817184410 \\ Fax: +4881 7478646 \\ E-mail: iwonabojar75@gmail. \\ com
}




\section{Introduction}

Androgens play a primary role in female physiopathology. The age-related reduction in the production of ovarian and adrenal androgens may significantly affect women's health. The decline of circulating androgens results from a combination of two events: reduced ovarian production and aged-related decline in adrenal androgen synthesis. The relative androgen deficiency in pre- and postmenopausal women may of course induce impairment of sexual function, but it is fairly well known to influence brain health and may contribute to reduced cognitive functions [1].

In both the central nervous system and peripheral tissues, there are multiple ways whereby androgens target their specific actions through a particular tropism of the brain areas that are involved in behavior and cognition [2].

Thus the brain for quite a while has been considered an androgen-sensitive tissue and, what is even more intriguing, shows an age-related decrease in androgen concentration. This has been proved in the studies of the level of testosterone (TTE) as well as its metabolite dihydrotestosterone (DHT) in the brains of rodents [3] and humans [4]. The concept of "female androgen insufficiency disorder" was used for the first time in 2001 [5]. Androgen deficiency can occur in women at any age but especially in menopause. Clinical signs and symptoms of low androgen exposure seem to be most pronounced in the postmenopausal period.

It has been determined that androgens play numerous roles in neuroprotection of the brain, which can be essential for determining their protective role observed in Alzheimer's disease. Androgens' positive impact on neurons includes: (1) promoting the growth of neurons, rebuilding axons and synaptic function, (2) protection against loss of neurons, as well as (3) regulation of development of pathologies that cause Alzheimer's disease, including amyloid- $\beta(A \beta)$ accumulation in the brain. Various experimental models have led to the conclusion that androgens stimulate neurons' growth and maturity $[6,7]$. Furthermore, androgens are strong synaptic transmitters, including regulation of long-term potentialization in the hippocampus [8-10]. In some experimental models they also accelerate regeneration of axons in damaged motor neurons $[11,12]$. Another function of androgens, potentially important for development of Alzheimer's and other neurodegenerative diseases, is protection against neuron loss. In many, though not all, experiments $[13,14]$ androgens considerably weakened neuron damage caused by oxidative stress and $A \beta$ toxicity $[15,16]$. Still, androgens showed a neuroprotective effect only in selected models of neuron death in vivo. For instance, in the experimental model of DHT they reduced neu- ron damage in the hippocampus [17]. However, androgens also accelerated cell death in the ischemic stroke model [18] and either had a negative impact or did not improve the vitality of dopaminergic neurons in the midbrain [19]. It remains unexplained why different models show different regulation of neuron livability by androgens. One hypothesis states that androgen-regulated neuroprotection is limited to certain types of cell death, which include apoptosis [20], but may not include effects of oxidative stress [21]. Moreover, changeability of neuroprotection may reflect the different effects of androgens in different brain areas or subpopulations of neurons [7].

Androgens regulate key factors of Alzheimer's disease pathogenesis such as $A \beta$ accumulation, and thus may prevent the development of the disease. Initial results [22] confirmed in subsequent studies [23] showed that anti-androgen therapy of prostate cancer led to increased levels of circulating $A \beta$. Testosterone also controls the level of $A \beta$ in cerebrospinal fluid and blood plasma of rodents after orchidectomy [24]. Similar results have been observed among men as part of the biological process of aging. DHT level lowering with age was associated with a significant increase of $A \beta$ level in the brain [3]. Testosterone- or DHT-based treatment protected the rodent's brain from $A \beta$ accumulation [25].

Androgens can reduce $A \beta$ levels also by influencing the production and metabolism of estrogens. At least part of the influence testosterone has on the central nervous system depends on its transformation to estradiol as done by aromatase (E2) $[26,27]$. A comparative study of gonadal steroids' influence on $A \beta$ level proved that estrogens, testosterone and DHT considerably reduce $A \beta$ level, testosterone being the most and E2 the least effective [25].

Dehydroepiandrosterone (DHEA) and its sulfate bound form (DHEAS) are produced both in gonads and in the brain. Dehydroepiandrosterone easily crosses the brain-blood barrier and in part is also produced locally in the brain tissue. Dehydroepiandrosterone is not just a pre-hormone of the adrenals, but rather a hormone, and it modulates a series of biological processes, with a remarkable tropism for the central nervous system. It has been reported that its administration can increase feelings of well-being and is useful in ameliorating atypical depressive disorders. It has neuroprotective and antiglucocorticoid activity and modifies immune reactions, and some authors have also reported its role in degenerative brain diseases [28].

In the brain DHEA is thus a neurosteroid that acts as a modulator of neurotransmitter receptors, such as $\gamma$-aminobutyric acid type A, N-methyl-D-aspartate (NMDA), and sigma-1 receptors. Both in vitro and in vivo DHEA was shown to be involved 
in neuroprotection, neurite growth, neurogenesis and neuronal survival, apoptosis, catecholamine synthesis and secretion. It was proved to have antioxidant and anti-inflammatory properties [29].

In the vessels, DHEA binds with high affinity to the endothelial cell membrane, and structurally related steroids. Binding of DHEA to the cell membrane is coupled to recruitment of $G$ proteins that mediate the rapid activation of intracellular signaling cascades [30].

Significant age-related decline in serum DHEA suggested that a deficiency of these steroids may be causally related to the development of a series of diseases which are generally associated with aging. Postulated consequences of low DHEA include insulin resistance, obesity, cardiovascular disease, cancer, reduction of the immune defense as well as psychosocial problems such as depres sion and a general deterioration in health and especially cognitive function [2].

There is also growing evidence in the literature that a low DHEAS level, representing the most abundant sex steroids in plasma in humans, negatively correlates with multiple domains of function in pre- and postmenopausal women [31].

Similarly, in a cross-sectional study, higher endogenous DHEAS levels are independently and favorably associated with several measures of cognitive function and well-being [32].

Epidemiological studies suggest that 15-40\% of cases of Alzheimer-type dementia may have a genetic component to their etiology. Still, most instances of Alzheimer's disease represent the sporadic form (60-85\%) with more complex inheritance type and multi-factor etiology [33]. Genes that have an impact on the risk of disease development include E apolipoprotein (APOE) located on chromosome 19 [34, 35]. E apolipoprotein (apoE) is a polymorphic protein which takes three isomorphic forms within the human body: apoE2, apoE3 and apoE4, encoded by three allelic sets of APOE: $\varepsilon 2, \varepsilon 3$ and $\varepsilon 4$. APOE's role in the pathomechanism of $A D$ is based on participation in metabolism and distribution of $A \beta$. ApoE is produced in the brain by astrocytes and microglia, and then undergoes lipidation. Depending on the isoform, apoE combined with $A \beta$ causes either accumulation of the latter in the form of amyloid plaques, or its distribution to cerebrospinal liquid. Using a lipoprotein binding unit, apoE can build a complex with $A \beta$ and help cells select it during endocytosis. ApoE may also intensify microglia and astrocytes' ability to clean up $A \beta$ [36]. It is believed that apoE can also control $A \beta$ transport through the blood-brain barrier [37]. Various apoE isoforms are involved in these processes to a different degree. ApoE also influences other processes within the central nervous system, which are potentially related to Alzheimer's disease development: neurotransmission, neurotoxicity, tau protein hyperphosphorylation and inflammatory processes in the central nervous system [38].

Presence of apoE4 facilitates accumulation of $\beta$-amyloid in the brain, and, together with the neurodegenerative changes described above, constitutes a risk factor of development of cognitive disorders and dementia [39]. At the same time, this risk is reduced by presence of the apoE2 isoform. It has been observed that $\beta$-amyloid begins to accumulate earlier among patients with APOE $\varepsilon 4$ than among noncarriers of APOE $\varepsilon 4$ [40]. The authors have proved that carrying APOE $\varepsilon 4$ is linked to increased $\beta$-amyloid accumulation in lobar cerebral blood vessels located peripherally [41]. The latest studies confirm the thesis that presence of apoE4 is a significant risk factor of $\mathrm{MCl}$ (mild cognitive impairment) conversion to dementia [34, 35, 42].

Studies assessing estrogens' influence on neuropsychological functions among women in the menopausal period showed that this process may depend on differences in APOE polymorphism. Estradiol stimulates the production of apoE $[43,44]$, and accelerates the growth of nerves [45]. These relationships point to apoE's significant role in estrogen-stimulated neuron growth.

As we already mentioned, androgens are key to estrogens' production and metabolism among women in the postmenopausal period. Therefore, it can be supposed, that they will also, like estrogens, play an important role in development of brain changes that lead to dementia. Although current studies still do not describe APOE polymorphism in great detail, the phenomenon can constitute a significant part of the procedure that enables identification of patients in the menopausal and postmenopausal period, whose cognitive disorders may successfully be prevented or treated by means of androgen-based therapy.

The aim of this research was to analyze cognitive functions in relation to TTE and DHEA levels among women in the postmenopausal period in correlation with polymorphism of the $E$ apolipoprotein gene as a risk factor for dementia development.

\section{Material and methods}

\section{Study group}

The study was conducted in 2011 at the Institute of Rural Health in Lublin. The study group comprised women from south-eastern Poland. The criteria of inclusion in the study were as follows: age 50-65, good general health, education level at least completed elementary. The women were also included in the study group based on clinical symptoms (minimum 2 years from the 
last menstrual period) and based on the criterion of follicle-stimulating hormone (FSH) level (FSH > $30 \mathrm{mlU} / \mathrm{ml}$ ). The criteria for exclusion from the study were as follows: active cancerous disease within the period of 5 years before recruitment; mental diseases in medical history, including depression before menopause; addiction to drugs and alcohol; diagnosed nosologic unit with the symptoms of dementia. At the stage of qualification for the study, a brief Montreal Cognitive Assessment scale was conducted in order to include patients who did not show features of dementia [46]. The Montreal Cognitive Assessment (MoCA) scale for evaluation of cognitive functions was designed as a quick screening instrument for the evaluation of mild cognitive dysfunctions, with a Polish adaptation of the scale by Magierska et al. The maximum score in this test is 30 , and a score of 26 or more is considered as normal. All the women included in the study obtained more than 26 in the MoCA test.

\section{Neuropsychological assessment}

Cognitive functions were evaluated using the diagnostic instrument Central Nervous System-Vital Signs (CNS-VS) (Polish version) [47] with software by CNS Vital Signs (1829 East Franklin St., Bldg. 500, Chapel Hill, NC 27514, USA). The instrument in the form of a battery of computer tests is standardized, has been subjected to the full validation procedure, and possesses a Polish adaptation. The entire research procedure using a computer was performed in Polish. The report concerning test results is published in English. CNS-VS covers the following tests: Verbal Memory Test (VBM), the test examining motor functioning - Finger Tapping Test (FTT), Symbol Digit Modalities Test (SDMT), Stroop Test (ST), Shifting Attention Test (SAT), Continuous Performance. CNS-VS assesses nine cognitive functions: memory, verbal memory, visual memory, processing speed, executive functions, psychomotor speed, reaction time, complex attention, and cognitive flexibility. Based on five of these functions - memory, psychomotor speed, reaction time, complex attention, and cognitive flexibility - the Neurocognition Index (NCI) is calculated. The computer data from the CNS-VS test provide: raw results, standardized results, percentiles, and evaluations according to the 5-point scale for each of the nine cognitive functions examined and the Neurocognitive Index. These evaluations are as follows: above average (more than 109 standardized scores), average (90-109), below average (80-89), low (70-79), very low (less than 70).

\section{Androgens}

The subjects had TTE and DHEA levels in their blood plasma determined by an accredited labo- ratory. Norms for women in the postmenopausal period are: TTE 14-76 ng/dl and DHEA 1.3-9.8 ng/ $\mathrm{ml}$. Due to the fact that a number of women displayed TTE and DHEA levels which remained within the norm, the norm ranges have been subdivided into three subranges of equal spread: low normal, middle normal and high normal.

\section{Genetic analysis}

The other variable in our study design was APOE polymorphism. Genetic studies were performed in the Unit of Molecular Biology of the Department of Zoonoses in the Institute of Rural Health in Lublin.

Isolated genomic DNA was extracted from $0.2 \mathrm{ml}$ of human whole blood using a QIAamp DNA Blood Mini Kit (Qiagen, USA) according to the producer's instructions.

Multiplex polymerase chain reaction (PCR) was done according to Yang et al. [48] with some modifications. PCR reactions were performed in a single reaction tube with six primers consisting of two common primers and two specific primers for each of two single nucleotide polymorphism (SNP) sites. The multiplex PCR reaction was performed in a $50 \mu \mathrm{l}$ reaction volume which contained the following mix of reagents: $1.25 \mathrm{U}$ of Taq DNA polymerase (Qiagen, USA), 1× PCR buffer containing $15 \mathrm{mM} \mathrm{MgCl}$ and $1 \times \mathrm{Q}$ buffer (all from Qiagen, USA), $0.2 \mathrm{mM}$ each of dNTP (Fermentas, Lithuania), $0.5 \mu \mathrm{M}$ of each of six primers: FO, RO, FI-1, RI-1, $\mathrm{FI}-2, \mathrm{RI}-2$ (Eurogentec, Seraing, Belgium), nuclease-free water (Applied Biosystems, USA) and $5 \mu \mathrm{l}$ of DNA. The reaction was performed in a C1000 Thermal Cycler (Bio-Rad) under the following conditions: initial denaturation at $95^{\circ} \mathrm{C}$ for 5 min, then 35 cycles (denaturation $95^{\circ} \mathrm{C}$ for $30 \mathrm{~s}$, annealing at $60^{\circ} \mathrm{C}$ for $30 \mathrm{~s}$, elongation at $72^{\circ} \mathrm{C}$ for $60 \mathrm{~s}$ ), and a final extension step at $72^{\circ} \mathrm{C}$ for $7 \mathrm{~min}$. The reaction products were detected in $2.5 \%$ agarose gels in the standard electrophoresis conditions. After ethidium bromide staining, the strips were read under UV light. The size of the amplified DNA fragment using two common outer primers (FO and RO) was 514 bp. Obtained DNA amplicons flanked by each of two sets of allele-specific inner primers (FI-1/RI-1 and FI-2/RI-2) showed different types of polymorphisms: $444 \mathrm{bp}, 307 \mathrm{bp}$ and $115 \mathrm{bp}$ for $\varepsilon 3 /$ \&4; $307 \mathrm{bp}$ and $115 \mathrm{bp}$ for $\varepsilon 3 / \varepsilon 3 ; 444 \mathrm{bp}$ and 307 bp for $\varepsilon 4 / \varepsilon 4 ; 307$ bp, 253 bp and 115 bp for $\varepsilon 2 / \varepsilon 3$; 444 bp, 307 bp, 253 bp and 115 bp for $\varepsilon 2 / \varepsilon 4$.

\section{Statistical analysis}

Both statistical analysis and diagrams were developed using Statistica software. The F test of ANOVA (analysis of variance) was used to determine whether age, BMI (body mass index), andro- 
gen level and cognitive functions depend on APOE polymorphism. In order to determine whether level of education and ranges of androgen norms depend on APOE polymorphism, the researchers applied the $\chi^{2}$ test of stochastic independence. Pearson's correlation coefficient was chosen to test for a linear correlation between androgen and $\mathrm{NCl}$ levels and cognitive functions in the subject group in total and in groups of APOE polymorphism. Due to lack of a linear correlation between DHEA, $\mathrm{NCl}$ and cognitive functions, the $\mathrm{F}$ test of ANOVA was used to determine whether $\mathrm{NCl}$ and cognitive functions depend on DHEA norm ranges. Finally, the $F$ test of two-way analysis of variance was applied to determine whether an interaction between APOE polymorphism and DHEA norm ranges influences $\mathrm{NCl}$ and cognitive functions.

Numbers ( $n$ ) and frequency distributions (\%) were presented for categorical variables. For continuous variables, means $(M)$ and standard deviations $(S D)$ were calculated. The former reflects the average level, while the latter measures the degree of measures' dispersion around the arithmetical average or 0.95 confidence intervals. Due to the large population size of the subject group $(N=402)$, the author applied the normal distribution of parameter estimators. In statistical tests, the significance level was set at 0.05 .
Consent for the study was obtained from the Bioethical Committee at the Institute of Rural Health in Lublin.

\section{Results}

Four hundred and two women participated in the research. Most of them (253, i.e. 62.93\%) had the $\varepsilon 3 / \varepsilon 3$ APOE allele configuration. Another 86 had the $\varepsilon 3 / \varepsilon 4$ (64) or $\varepsilon 4 / \varepsilon 4$ (22) APOE allele configuration, which constituted approximately $21.39 \%$ of the subject group. The $\varepsilon 2 / \varepsilon 3$ APOE allele configuration was observed among 63 (15.67\%) respondents.

The age of the women examined ranged from 50 to 65 years, with the average age of $56.5 \pm 3.5$ years. Average body mass index (BMI) value was $26.4 \pm 3.9$. Incidence of APOE allele configurations was not correlated with age or BMI, though a correlation with education level was observed (Table I). The better educated a woman was, the more frequently she had the $\varepsilon 2 / \varepsilon 3$ or $\varepsilon 3 / \varepsilon 3$ APOE allele configuration, and the least frequently the $\varepsilon 3 / \varepsilon 4$ or $\varepsilon 4 / \varepsilon 4$ APOE allele configuration.

The participants of the research had an average TTE level of $40.45 \pm 14.08 \mathrm{ng} / \mathrm{dl}$, and average DHEA level of $7.18 \pm 4.61 \mathrm{ng} / \mathrm{ml}$ (Table I). The subject group did not include patients with androgen levels below the norm. Only 4 women had TTE

Table I. Characteristics of the subject group in total and according to polymorphism of E apolipoprotein gene

\begin{tabular}{|c|c|c|c|c|c|c|c|}
\hline \multirow[t]{2}{*}{ Feature } & \multirow[t]{2}{*}{ Categories } & \multirow[t]{2}{*}{$\begin{array}{c}\text { Total } \\
(N=402)\end{array}$} & \multirow[t]{2}{*}{$\begin{array}{c}\varepsilon 2 / \varepsilon 3 \\
(N=63)\end{array}$} & \multirow[t]{2}{*}{$\begin{array}{c}\varepsilon 3 / \varepsilon 3 \\
(N=253)\end{array}$} & \multirow{2}{*}{$\begin{array}{c}\varepsilon 3 / \varepsilon 4 \text { or } \\
\varepsilon 4 / \varepsilon 4 \\
(N=86)\end{array}$} & \multicolumn{2}{|c|}{$\begin{array}{l}\text { Significance } \\
\text { of differences }\end{array}$} \\
\hline & & & & & & test & $p$ \\
\hline $\begin{array}{l}\text { Age } \\
\text { [years] }\end{array}$ & $M \pm S D$ & $56.5 \pm 3.5$ & $56.4 \pm 33$ & $56.6 \pm 3.6$ & $56.1 \pm 3.6$ & $F=0.712$ & 0.491 \\
\hline \multirow{4}{*}{$\begin{array}{l}\text { Level of } \\
\text { education }\end{array}$} & Primary, $n(\%)$ & $13(3.23)$ & $1(7.69)$ & $4(30.77)$ & $8(38.46)$ & \multirow[t]{4}{*}{$\chi^{2}=26.731$} & \multirow[t]{4}{*}{$<0.001$} \\
\hline & Basic vocational, $n(\%)$ & $37(9.20)$ & $3(8.11)$ & $23(62.16)$ & $11(21.62)$ & & \\
\hline & Secondary, $n(\%)$ & $181(45.02)$ & $32(17.68)$ & $103(56.91)$ & $46(18.78)$ & & \\
\hline & Tertiary, $n(\%)$ & $171(42.54)$ & $27(15.79)$ & $123(71.93)$ & $21(9.94)$ & & \\
\hline $\mathrm{BMI}\left[\mathrm{kg} / \mathrm{m}^{2}\right]$ & $M \pm S D$ & $26.4 \pm 3.9$ & $26.6 \pm 3.8$ & $26.4 \pm 3.8$ & $26.1 \pm 4.5$ & $F=0.387$ & 0.679 \\
\hline \multirow[t]{6}{*}{ TTE } & $M \pm S D[n g / m l]$ & $40.45 \pm 14.08$ & $40.11 \pm 14.42$ & $39.91 \pm 13.66$ & $42.29 \pm 15.04$ & $F=0.938$ & 0.392 \\
\hline & Below normal, $n(\%)$ & $0(0.00)$ & $0(0.00)$ & $0(0.00)$ & $0(0.00)$ & \multirow[t]{5}{*}{$\chi^{2}=9.918$} & \multirow[t]{5}{*}{0.128} \\
\hline & Low normal, $n(\%)$ & $152(37.81)$ & $27(42.86)$ & $95(37.55)$ & $30(34.88)$ & & \\
\hline & Medium normal, $n(\%)$ & $191(47.51)$ & $24(38.10)$ & $129(50.99)$ & $38(44.19)$ & & \\
\hline & High normal, $n$ (\%) & $55(13.68)$ & $11(17.46)$ & $26(10.28)$ & $18(20.93)$ & & \\
\hline & Above normal, $n(\%)$ & $4(1.00)$ & $1(1.59)$ & $3(1.19)$ & $0(0.00)$ & & \\
\hline \multirow[t]{6}{*}{ DHEA } & $\mathrm{M} \pm \mathrm{SD}[\mathrm{ng} / \mathrm{ml}]$ & $7.18 \pm 4.61$ & $6.30 \pm 3.79$ & $7.48 \pm 4.56$ & $6.93 \pm 5.19$ & $F=1.801$ & 0.167 \\
\hline & Below normal, $n(\%)$ & $0(0.00)$ & $0(0.00)$ & $0(0.00)$ & $0(0.00)$ & \multirow[t]{5}{*}{$\chi^{2}=8.507$} & \multirow[t]{5}{*}{0.203} \\
\hline & Low normal, $n(\%)$ & $125(31.09)$ & $21(33.33)$ & $69(27.27)$ & $35(40.70)$ & & \\
\hline & Medium normal, n (\%) & $113(28.11)$ & $20(31.75)$ & $74(29.25)$ & 19 (22.09) & & \\
\hline & High normal, $n(\%)$ & $82(20.40)$ & $14(22.22)$ & $54(21.34)$ & $14(16.28)$ & & \\
\hline & Above normal, $n(\%)$ & $82(20.40)$ & $8(12.70)$ & $56(22.13)$ & $18(20.93)$ & & \\
\hline
\end{tabular}


Table II. Cognitive domains (standard stores) according to polymorphism of E apolipoprotein gene

\begin{tabular}{|c|c|c|c|c|c|c|}
\hline \multirow{3}{*}{$\begin{array}{l}\text { Cognitive function } \\
\mathrm{NCl}\end{array}$} & \multirow{3}{*}{$\begin{array}{l}\text { Total } \\
.10 \pm 1.60\end{array}$} & \multirow{2}{*}{\multicolumn{2}{|c|}{$\begin{array}{c}\varepsilon 2 / \varepsilon 3 \quad \varepsilon 3 / \varepsilon 3 \\
M \pm 0.95 \text { confidence interval }\end{array}$}} & \multirow{3}{*}{$\begin{array}{c}\varepsilon 3 / \varepsilon 4 \\
\text { or } \varepsilon 4 / \varepsilon 4 \\
77.65 \pm 4.25\end{array}$} & \multicolumn{2}{|c|}{$\begin{array}{c}\text { Significance } \\
\text { of differences }\end{array}$} \\
\hline & & & & & \multirow{2}{*}{$\begin{array}{c}\boldsymbol{F} \\
12.578\end{array}$} & \multirow{2}{*}{$\begin{array}{c}p \\
<0.001\end{array}$} \\
\hline & & $90.65 \pm 4.03$ & $84.66 \pm 1.73$ & & & \\
\hline Memory & $90.05 \pm 1.55$ & $90.68 \pm 4.13$ & $90.53 \pm 1.87$ & $88.20 \pm 3.61$ & 0.755 & 0.471 \\
\hline Verbal memory & $91.27 \pm 1.75$ & $91.32 \pm 4.80$ & $91.36 \pm 2.18$ & $90.97 \pm 3.70$ & 0.016 & 0.984 \\
\hline Visual memory & $93.12 \pm 1.49$ & $94.46 \pm 2.93$ & $93.60 \pm 1.91$ & $90.72 \pm 3.54$ & 1.432 & 0.240 \\
\hline Processing speed & $79.14 \pm 1.40$ & $82.51 \pm 3.63$ & $78.41 \pm 1.77$ & $78.81 \pm 2.85$ & 2.115 & 0.122 \\
\hline Executive functioning & $79.21 \pm 2.46$ & $90.17 \pm 5.20$ & $80.33 \pm 2.87$ & $67.88 \pm 6.06$ & 16.113 & $<0.001$ \\
\hline Psychomotor speed & $83.28 \pm 1.79$ & $93.46 \pm 3.45$ & $82.24 \pm 2.02$ & $78.86 \pm 4.93$ & 13.459 & $<0.001$ \\
\hline Reaction time & $86.82 \pm 1.61$ & $93.05 \pm 4.26$ & $86.47 \pm 1.87$ & $83.30 \pm 3.85$ & 6.744 & 0.001 \\
\hline Complex attention & $81.58 \pm 2.82$ & $92.51 \pm 5.70$ & $83.79 \pm 3.14$ & $67.09 \pm 7.63$ & 17.404 & $<0.001$ \\
\hline Cognitive flexibility & $78.07 \pm 2.56$ & $89.03 \pm 5.74$ & $79.27 \pm 2.97$ & $66.52 \pm 6.28$ & 15.153 & $<0.001$ \\
\hline
\end{tabular}

above the norm (1.00\% of the subject group). The DHEA above the norm was observed in 82 cases, i.e. among one fifth of the group. Almost all the women had a normal TTE level (99.00\%), and the majority had a normal DHEA level (79.60\%). Looking closer at the TTE norm, most patients had middle normal values of the norm (47.51\%), fewer had low normal (37.81\%), and the fewest had high normal (13.86\%). Analysis of the DHEA norm shows that most subjects had low normal values (31.09\%), slightly fewer had middle normal $(28.11 \%)$, and the fewest had high normal (20.40\%). Levels of TTE and DHEA androgens did not depend on APOE polymorphism. A statistically significant positive correlation was identified between TTE and DHEA $(r=0.211 ; p<0.001)$, which translates into higher TTE levels accompanying higher DHEA levels observed typically among women in the postmenopausal period.

The average value of the neurocognitive index in the subject group was $84.10 \pm 16.35$, which meant low average (Table II). The lowest scores were observed for cognitive flexibility, processing speed and executive functioning (average results were lower than 80 points, which meant low scores). The women examined achieved the highest results for memory as well as visual and verbal memory (average scores above 90 points, i.e. middle). The domains in which the women scored middle results included complex attention, psychomotor speed and reaction time (average scores between 80 and 90 points, meaning low average).

The results of $\mathrm{NCl}$ and 5 cognitive functions (apart from three types of memory and processing speed) were significantly dependent on APOE polymorphism (Table II). Highest scores in $\mathrm{NCl}$, executive functioning, psychomotor speed, reaction time, complex attention and cognitive flexibility were observed among women with $\varepsilon 2 / \varepsilon 3$ alleles, lower among those with $\varepsilon 3 / \varepsilon 3$ alleles, and the lowest among those with $\varepsilon 3 / \varepsilon 4$ or $\varepsilon 4 / \varepsilon 4$ alleles (Figure 1).

In all cases, testosterone level in the blood serum was negatively correlated with the results of $\mathrm{NCl}$ and two cognitive functions: memory and psychomotor speed (Table III). The researchers observed negative linear correlations of TTE level and results of $\mathrm{NCl}$ and all cognitive functions except processing speed and reaction time among women with $\varepsilon 4$ APOE. Typically, the higher the TTE level was, the lower were these scores among wom-

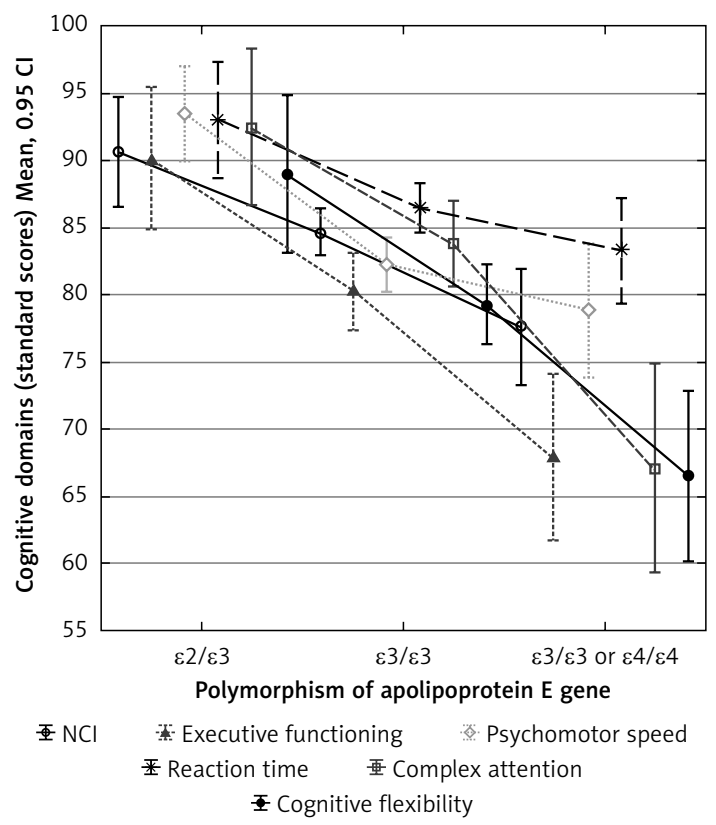

Figure $1 . \mathrm{NCl}$ and cognitive functions dependent on polymorphism of apolipoprotein E gene 
Table III. Correlation coefficient between cognitive domains (standard stores) and TTE (ng/dl) among the subjects in total and according to $\mathrm{E}$ apolipoprotein polymorphism

\begin{tabular}{|c|c|c|c|c|c|c|c|c|}
\hline \multirow[t]{2}{*}{ Domain } & \multicolumn{2}{|c|}{ Total } & \multicolumn{2}{|c|}{$\varepsilon 2 / \varepsilon 3$} & \multicolumn{2}{|c|}{$\varepsilon 3 / \varepsilon 3$} & \multicolumn{2}{|c|}{$\varepsilon 3 / \varepsilon 4$ or $\varepsilon 4 / \varepsilon 4$} \\
\hline & $r$ & $p$ & $r$ & $p$ & $r$ & $p$ & $r$ & $p$ \\
\hline $\mathrm{NCl}$ & -0.110 & 0.028 & 0.130 & 0.309 & -0.062 & 0.324 & -0.303 & 0.005 \\
\hline Memory & -0.132 & 0.008 & 0.216 & 0.089 & -0.147 & 0.019 & -0.319 & 0.003 \\
\hline Verbal memory & -0.091 & 0.068 & 0.191 & 0.134 & -0.110 & 0.081 & -0.258 & 0.017 \\
\hline Visual memory & -0.096 & 0.054 & 0.142 & 0.266 & -0.072 & 0.253 & -0.256 & 0.018 \\
\hline Processing speed & -0.040 & 0.425 & 0.021 & 0.870 & -0.020 & 0.746 & -0.142 & 0.191 \\
\hline Executive functioning & -0.037 & 0.458 & 0.155 & 0.224 & 0.028 & 0.658 & -0.225 & 0.037 \\
\hline Psychomotor speed & -0.213 & $<0.001$ & -0.302 & 0.016 & -0.162 & 0.010 & -0.280 & 0.009 \\
\hline Reaction time & -0.035 & 0.490 & 0.110 & 0.392 & -0.025 & 0.696 & -0.127 & 0.244 \\
\hline Complex attention & -0.051 & 0.311 & 0.192 & 0.132 & 0.037 & 0.555 & -0.274 & 0.011 \\
\hline Cognitive flexibility & -0.036 & 0.468 & 0.161 & 0.207 & 0.029 & 0.643 & -0.235 & 0.030 \\
\hline
\end{tabular}

en with $\varepsilon 4$ APOE. Furthermore, women with $\varepsilon 3 /$ $\varepsilon 3$ APOE showed a negative correlation between TTE, memory and psychomotor speed, whereas those with $\varepsilon 2 / \varepsilon 3$ showed a negative correlation between TTE and psychomotor speed only.

No linear correlations were noted between DHEA level $(\mathrm{ng} / \mathrm{ml})$ and results of $\mathrm{NCl}$ and any cognitive function (standard scores). This pertains to both the subject group in total, and the three groups identified according to APOE polymorphism $(p>0.05)$. When $\mathrm{NCl}$ and cognitive functions (standard stores) were analyzed according to the four DHEA norm ranges (low normal, middle normal, high normal and above normal), significant relations were identified between memory as well as verbal and visual memory (Table IV). Women with a high normal level of DHEA scored significantly better in these domains than other participants (with low, medium and above normal level of DHEA, with no significant difference with regard to these domains) (Figure 2). Interaction between APOE polymorphism and norm ranges of DHEA did not have any significant influence on the scores of $\mathrm{NCl}$ and cognitive functions as observed among women in the postmenopausal period (Table IV).

\section{Discussion}

The relationship between APOE polymorphism and education level has been evaluated in many

Table IV. Cognitive domains (standard stores) according to DHEA and polymorphism of E apolipoprotein

\begin{tabular}{|c|c|c|c|c|c|c|c|c|}
\hline \multirow{4}{*}{$\begin{array}{l}\text { Cognitive function } \\
\mathrm{NCl}\end{array}$} & \multicolumn{6}{|c|}{ DHEA } & \multirow{2}{*}{\multicolumn{2}{|c|}{$\begin{array}{l}\text { Interaction } \\
\text { (DHEA*APOE) }\end{array}$}} \\
\hline & $\begin{array}{l}\text { Low } \\
\text { normal }\end{array}$ & $\begin{array}{l}\text { Medium } \\
\text { normal }\end{array}$ & $\begin{array}{l}\text { High } \\
\text { normal }\end{array}$ & $\begin{array}{l}\text { Above } \\
\text { normal }\end{array}$ & \multicolumn{2}{|c|}{$\begin{array}{l}\text { Significance of } \\
\text { differences }\end{array}$} & & \\
\hline & \multicolumn{4}{|c|}{$M \pm 0.95$ Confidence Interval } & $F$ & $p$ & $F$ & $p$ \\
\hline & $82.61 \pm 2.80$ & $83.63 \pm 3.30$ & $86.82 \pm 3.02$ & $84.30 \pm 3.65$ & 1.138 & 0.333 & 0.692 & 0.656 \\
\hline Memory & $88.91 \pm 2.95$ & $87.58 \pm 2.63$ & $97.71 \pm 2.98$ & $87.55 \pm 3.47$ & 8.685 & $<0.001$ & 0.720 & 0.634 \\
\hline Verbal memory & $91.07 \pm 3.12$ & $89.92 \pm 3.25$ & $96.28 \pm 3.53$ & $88.41 \pm 4.16$ & 3.102 & 0.027 & 1.540 & 0.164 \\
\hline Visual memory & $90.97 \pm 3.13$ & $91.53 \pm 2.17$ & $99.97 \pm 2.99$ & $91.74 \pm 3.26$ & 7.283 & $<0.001$ & 1.029 & 0.406 \\
\hline Processing speed & $79.06 \pm 2.24$ & $80.33 \pm 2.81$ & $76.93 \pm 3.17$ & $79.83 \pm 3.17$ & 0.981 & 0.402 & 1.378 & 0.222 \\
\hline Executive functioning & $74.86 \pm 4.54$ & $78.64 \pm 5.04$ & $83.46 \pm 4.94$ & $82.39 \pm 4.77$ & 2.519 & 0.058 & 1.398 & 0.214 \\
\hline Psychomotor speed & $83.22 \pm 3.29$ & $85.09 \pm 3.13$ & $80.33 \pm 3.96$ & $83.80 \pm 4.16$ & 1.103 & 0.348 & 1.605 & 0.144 \\
\hline Reaction time & $85.55 \pm 2.62$ & $87.74 \pm 3.42$ & $88.46 \pm 2.97$ & $85.84 \pm 3.89$ & 0.736 & 0.531 & 1.699 & 0.120 \\
\hline Complex attention & $77.65 \pm 5.46$ & $81.28 \pm 5.42$ & $86.39 \pm 5.39$ & $83.19 \pm 6.02$ & 1.629 & 0.182 & 1.336 & 0.240 \\
\hline Cognitive flexibility & $73.79 \pm 4.77$ & $77.77 \pm 5.16$ & $82.74 \pm 5.03$ & $80.34 \pm 5.21$ & 2.215 & 0.086 & 0.944 & 0.463 \\
\hline
\end{tabular}


studies. Similarly, in the analysis of our material, the better educated a woman was, the more frequently did she display the $\varepsilon 2 / \varepsilon 3$ or $\varepsilon 3 / \varepsilon 3$ APOE allele configuration, and the least frequently the $\varepsilon 3 / \varepsilon 4$ or $\varepsilon 4 / \varepsilon 4$ APOE allele configuration. It is known that the presence of apoE4 favors the deposition of $\beta$-amyloid in the brain and neurodegenerative changes, and is a risk factor for the development of cognitive disorders and dementia. Similarly, the occurrence of the isoform apoE2 decreases this risk [39]. It is an interesting fact that the level of education influences the health education and therefore women with a longer education time make better health choices (e.g. obtain earlier diagnoses, get treated, adhere to treatment regimens), and therefore are at lower risk of developing a disease. This concerns such chronic diseases as atherosclerosis, hypertension, diabetes, etc. In this way, it may exert an effect, among others, on the development of cognitive disorders and dementia [49].

Scores in the five cognitive functions and $\mathrm{NCl}$ were significantly lower for women who had at least one APOE $\varepsilon 4$ allele. The higher the testosterone level was, the lower were the results at $\mathrm{NCl}$, memory and psychomotor speed. Possessing the APOE \&4 allele strengthened testosterone's negative impact on the results of $\mathrm{NCl}$ and most cognitive functions, excluding processing speed and reaction time. Interestingly, scores for psychomotor speed were negatively correlated with testosterone level, regardless of which APOE polymorphism $-\varepsilon 4 / \varepsilon 4$ or $\varepsilon 3 / \varepsilon 4, \varepsilon 3 / \varepsilon 3$, or $\varepsilon 2 / \varepsilon 3$ - was shown by the patient.

A large-scale population study based on 1276 middle-aged and elderly women proved that women with low scores in memory have a higher level of free testosterone [50], which is in line with the results of our own studies. Similarly, in the research by Ryan et al., better semantic memory performance was associated with higher total and free estradiol levels and a lower ratio of testosterone to estradiol. There were trends in the relationship between better verbal episodic memory and lower total testosterone and lower testosterone/estradiol ratio. Lower free testosterone levels were associated with greater 2-year improvement in verbal episodic memory; higher testosterone/ estradiol predicted greater semantic memory improvement [51].

Recent imaging studies however depict a slightly different influence of testosterone on brain activity. Davis et al. in their pilot study of healthy postmenopausal women stabilized on transdermal estrogen found that testosterone therapy is associated with reduced BOLD signal activation in key anatomical areas during functional magnetic resonance imaging (fMRI) verbal fluency and visuospatial tasks. This finding suggested that tes-

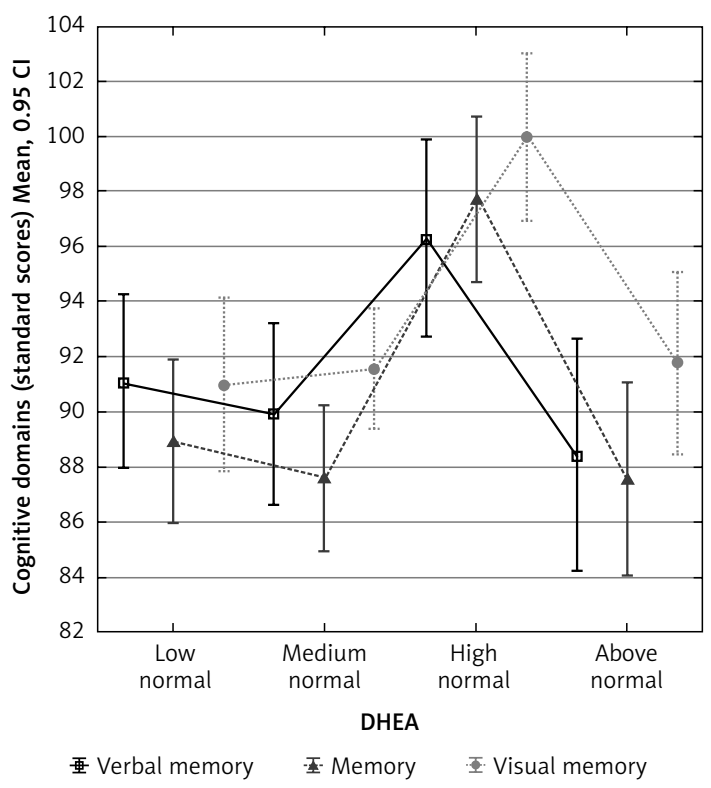

Figure 2. Memory, verbal and visual memory according to DHEA norm ranges

tosterone therapy facilitates the preservation of these specific components of cognitive function with less neuronal recruitment. In the setting of this study, testosterone seemed to be inducing neuroprotective effects. The role and interplay of testosterone with other hormones to preserve these aspects of cognitive function in postmenopausal women merit further study [52].

Female gender is an AD risk factor, and apoE4 is a factor that intensifies the risk if it co-occurs with female gender. Some sources claim that androgens and androgen-dependent sensory signals can protect from apoE4's detrimental influence on cognitive functions. Short periods of androgen application eliminate cognitive deficits among adult female mice displaying apoE4, whereas strong AR (androgen receptor) blockade led to sudden deterioration of cognitive functions among male mice with 84 APOE, and not with 83 APOE [53]. Moreover, expression of $\varepsilon 4$ APOE, and not $\varepsilon 3$ APOE, considerably weakened the cytosol bonds with $A R$ in the cerebral cortex. The data show that APOE $\varepsilon 4$ may interact with the androgen receptor, which can lead to a negative effect in some cognitive functions among patients with APOE $\varepsilon 4$. Bonds between testosterone and androgen receptors were found to be much weaker among mice with the $\varepsilon 4$ allele $[53,54]$. Such an effect could also explain the increasingly negative influence of higher testosterone levels on cognitive function scores among women in the postmenopausal period and with the APOE $\varepsilon 4$ allele.

Decrease of androgen level and its receptors as resulting from castration may have a positive impact since it reduces APOE $\varepsilon 4$ interaction with the androgen receptor. APOE $\varepsilon 4$ interaction with 
AR may also limit cells' sensitivity to signals transmitted through the androgen receptor. These data suggest that women can be more prone to the detrimental cognitive effects caused by APOE $\varepsilon 4$ presence than men, even when displaying lower concentrations of endogenous androgens [55]. Nevertheless, another study confirmed that both low testosterone level and testosterone's interaction with APOE 84 may increase the risk of Alzheimer's disease [56]. A similar link was observed in an experiment by Panizzon et al., conducted among middle-aged men. Significant positive associations were observed between free testosterone level and verbal episodic memory, as well as a significant interaction between free testosterone and APOE- $\varepsilon 4$ status. In $\varepsilon 4$ carriers free testosterone was positively associated with verbal episodic memory performance (story recall), whereas no association was observed in $\varepsilon 4$ noncarriers [57].

Experiments on animals showed that in the brain, and particularly in the hippocampus, testosterone influences the production and accumulation of $\beta$-amyloid [58]. It was noted that patients with at least one APOE $\varepsilon 4$ allele and a low testosterone level had the most limited capacity of the hippocampus. However, when compared to the groups with normal testosterone levels, this was not statistically significant. Testosterone as such did not influence the capacity of the hippocampus, but its importance grew when the interaction with APOE was considered. Interestingly, hippocampus capacity as observed among patients without the $\varepsilon 4$ allele and with a low testosterone level was considerably higher than in any other group [59]. This suggests that the link between APOE genotype, testosterone, AR and the role of the hippocampus is highly complex and it is still not comprehensively explained.

The concentrations of circulating testosterone are lower in males with at least one APOE $\varepsilon 4$ allele [60]. The decrease in endogenous testosterone after castration in mice carriers of APOE $\& 4$ causes behavioral disorders [55]. Similarly, pharmacological and genetic inhibition of AR function leads to behavioral disorders in mice with APOE $\varepsilon 4$, but not APOE $\varepsilon 3[53,61]$. In addition, a lower concentration of AR was observed in both male and female mice with APOE $\varepsilon 4$. Nevertheless, it is not known whether APOE $\varepsilon 4$ directly affects the concentration of $A R$, or in other ways disturbs androgen binding to AR [53]. The genotype APOE $\varepsilon 4$ is related to both a lower concentration of testosterone and inhibition of the effect of androgen on neurons.

Researchers suggested that the link between estrogens and decrease in cognitive functions observed among women in the postmenopausal period may be caused by the influence of androgens since in that group of patients estrogens come from the peripheral conversion of andro- gens' precursors [62]. An experiment was carried out to determine whether inhibition of testosterone conversion into estradiol alters testosterone's influence on cognitive functions. The researchers observed no clinically significant effects of testosterone-based treatment on attention functions, executive functions, psychomotor speed and working memory. However, instant memory, verbal memory and visual memory improved considerably. The experiment showed that aromatase inhibition by supplying letrozole did not have any impact on the cognitive function of healthy women treated with estrogens and testosterone [63].

Our study did not confirm any linear correlation between DHEA, NCI results and cognitive functions among women in total as well as in the groups divided according to particular APOE polymorphisms. Significant differences were observed in memory, verbal memory and visual memory in the three ranges of DHEA norms. The highest scores were obtained by patients with DHEA in the high norm and these results were, again, not related to APOE polymorphism the patients had.

Synthesis of DHEA in women occurs mainly in the adrenal cortex, DHEA being the main precursor of active estrogens after menopause. Reduction of DHEA synthesis performed by adrenal glands in the period of aging leads to reduced production of androgens and estrogens in peripheral tissues. It is suggested that this may also have an impact on cognitive functions in the postmenopausal period. Lower levels of DHEA and DHEAS were thought to be related to cognitive function disorders and higher incidence of such diseases as Alzheimer's disease among the elderly [64]. Among men [65] and healthy women after menopause [32], a higher endogenous level of DHEAS was linked to better cognitive abilities, which is in line with the results obtained in the present research. DHEA/S can help in some impaired domains of memory $[32,65]$; in the case of the present study it was memory, as well as verbal and visual memory. This supports the thesis that DHEA/S supplementation may improve cognitive function of the elderly. Nonetheless, other reports are not explicit when it comes to cognitive benefits from application of DHEA [66, 67]. Interestingly, postmortem examination of patients with Alzheimer's disease showed a higher level of DHEA in brain tissue and cerebrospinal fluid [68], particularly in the prefrontal cortex [69] and temporal lobes [70], than in the case of other patients. Furthermore, DHEA level was significantly higher in brain tissue of women when compared to that of men [70].

All these findings may contribute to the debate about the role of androgens and especially DHEA in female aging, with special attention to cognitive decline. The lack of definitive evidence of biological mechanisms and the existence of only a few studies that address these emerging 
issues of androgen/DHEA therapy in postmeno pausal women should encourage a new research approach with a critical analysis of the available literature. Concurrently, the design of new clinical trials, specifically planned on the overall brain health and especially cognition of symptomatic postmenopausal women and designed for the translation of basic science into clinical practice, is now a required step to move forward in the scientific debate of androgens in brain processing and senescence.

In conclusion, The higher testosterone level among women after menopause corresponds with lower scores for $\mathrm{NCl}$, memory and psychomotor speed. Moreover, the APOE $\varepsilon 4$ allele strengthened testosterone's negative influence on cognitive functions. In contrast, high or normal DHEA was related to better results for memory as well as verbal and visual memory in women after menopause. Furthermore, APOE polymorphism did not alter the relationship between DHEA level and scores for cognitive functions.

\section{Acknowledgments}

This study was financially supported by the Institute of Rural Health in Lublin, Poland.

\section{Conflict of interest}

The authors declare no conflict of interest.

\section{References}

1. Pluchino N, Carmignani A, Cubeddu A, Santoro A, Cela V, Errasti T. Androgen therapy in women: for whom and when. Arch Gynecol Obstet 2013; 288: 731-7.

2. Labrie F. Extragonadal synthesis of sex steroids: intracrinology. Ann Endocrinol (Paris) 2003; 64: 95-107.

3. Rosario ER, Chang L, Beckett TL, et al. Age-related changes in serum and brain levels of androgens in male Brown Norway rats. Neuroreport 2009; 20: 1534-7.

4. Rosario ER, Chang L, Head EH, Stanczyk FZ, Pike CJ. Brain levels of sex steroid hormones in men and women during normal aging and in Alzheimer's disease. Neurobiol Aging 2011; 32: 604-13.

5. Bachmann G, Bancroft J, Braunstein G, Burger H, Davis S, Dennerstein L. Female androgen insufficiency: thePrinceton consensus statement on definition, classification, and assessment. Fertil Steril 2002; 77: 660-6.

6. Peper JS, van den Heuvel MP, Mandl RC, Hulshoff Pol HE, van Honk J. Sex steroids and connectivity in the human brain: a review of neuroimaging studies. Psychoneuroendocrinology 2011; 36: 1101-13.

7. Vest RS, Pike CJ. Gender, sex steroid hormones, and Alzheimer's disease. Horm Behav 2012; 63: 301-7.

8. Hajszan T, MacLusky NJ, Leranth C. Role of androgens and the androgen receptor in remodeling of spine synapses in limbic brain areas. Horm Behav 2008; 53: 638-46.

9. Hatanaka Y, Mukai H, Mitsuhashi K, et al. Androgen rapidly increases dendritic thorns of CA3 neurons in male rat hippocampus. Biochem Biophys Res Commun 2009; 381: 728-32.
10. Schulz K, Korz V. Hippocampal testosterone relates to reference memory performance and synaptic plasticity in male rats. Front Behav Neurosci 2010; 4: 187.

11. Huppenbauer CB, Tanzer L, DonCarlos LL, Jones KJ. Gonadal steroid attenuation of developing hamster facial motoneuron loss by axotomy: equal efficacy of testosterone, dihydrotestosterone, and 17-beta estradiol. J Neurosci 2005; 25: 4004-13.

12. Marron TU, Guerini V, Rusmini P, et al. Androgen-induced neurite outgrowth is mediated by neuritin in motor neurones. J Neurochem 2005; 92: 10-20.

13. Cunningham RL, Giuffrida A, Roberts JL. Androgens induce dopaminergic neurotoxicity via caspase-3-dependent activation of protein kinase $\mathrm{C}$ delta. Endocrinology 2009; 150: 5539-48.

14. Gatson JW, Singh M. Activation of a membrane-associated androgen receptor promotes cell death in primary cortical astrocytes. Endocrinology 2007; 148: 2458-64.

15. Nguyen TV, Yao M, Pike CJ. Androgens activate mitogen-activated protein kinase signaling: role in neuroprotection. J Neurochem 2005; 94: 1639-51.

16. Park SY, Tournell C, Sinjoanu RC, Ferreira A. Caspase-3and calpain-mediated tau cleavage are differentially prevented by estrogen and testosterone in beta-amyloid-treated hippocampal neurons. Neuroscience 2007; 144: 119-27.

17. Ramsden M, Shin TM, Pike CJ. Androgens modulate neuronal vulnerability to kainate lesion. Neuroscience 2003; 122: 573-8.

18. Li X, O'Malley BW. Unfolding the action of progesterone receptors. J Biol Chem 2003; 278: 39261-4.

19. Johnson ML, Day AE, Ho CC, Walker QD, Francis R, Kuhn $\mathrm{CM}$. Androgen decreases dopamine neurone survival in rat midbrain. J Neuroendocrinol 2010; 22: 238-47.

20. Nguyen TV, Jayaraman A, Quaglino A, Pike CJ. Androgens selectively protect against apoptosis in hippocampal neurones. J Neuroendocrinol 2010; 22: 1013-22.

21. Cunningham RL, Macheda T, Watts LT, et al. Androgens exacerbate motor asymmetry in male rats with unilateral 6-hydroxydopamine lesion. Horm Behav 2011; 60: 617-24.

22. Gandy S, Almeida OP, Fonte J, et al. Chemical andropause and amyloid-beta peptide. JAMA 2001; 285: 2195-6.

23. Almeida OP, Waterreus A, Spry N, Flicker L, Martins RN. One year follow-up study of the association between chemical castration, sex hormones, beta-amyloid, memory and depression in men. Psychoneuroendocrinology 2004; 29: 1071-81.

24. Wahjoepramono EJ, Wijaya LK, Taddei K, et al. Distinct effects of testosterone on plasma and cerebrospinal fluid amyloid-beta levels. J Alzheimers Dis 2008; 15: 129-37.

25. Rosario ER, Carroll J, Pike CJ. Testosterone regulation of Alzheimer-like neuropathology in male 3xTg-AD mice involves both estrogen and androgen pathways. Brain Res 2010; 1359: 281-90.

26. Goodenough S, Engert S, Behl C. Testosterone stimulates rapid secretory amyloid precursor protein release from rat hypothalamic cells via the activation of the mitogen-activated protein kinase pathway. Neurosci Lett 2000; 296: 49-52.

27. Gouras GK, Xu H, Gross RS, et al. Testosterone reduces neuronal secretion of Alzheimer's beta-amyloid peptides. Proc Natl Acad Sci USA 2000; 97: 1202-5.

28. Stárka L, Dušková M, Hill M. Dehydroepiandrosterone: a neuroactive steroid. J Steroid Biochem Mol Biol 2015; 145: 254-60.

29. Genazzani AR, Pluchino N, Begliuomini S, Stomati M, Bernardi F, Pieri M. Long-term low-dose oral adminis- 
tration of dehydroepiandrosterone modulates adrenal response to adreno-corticotropic hormone in early and late postmenopausal women. Gynecol Endocrinol 2006; 22: 627-35.

30. Simoncini T, Mannella P, Fornari L, Varone G, Caruso A Genazzani AR. Dehydroepiandrosterone modulates endothelial nitric oxide synthesis via direct genomic and nongenomic mechanisms. Endocrinology 2003; 144: 3449-55.

31. Al-Azzawia F, Palacios S. Hormonal changes during menopause. Maturitas 2009; 63: 135-7.

32. Davis SR, Shah SM, McKenzie DP, Kulkarni J, Davison SL, Bell RJ. Dehydroepiandrosterone sulfate levels are associated with more favorable cognitive function in women. J Clin Endocrinol Metab 2008; 93: 801-8.

33. Holmes C. Genotype and phenotype in Alzheimer's disease. Br J Psychiatry 2002; 180: 131-4.

34. Norberg J, Graff C, Almkvist O, et al. Regional differences in effects of APOE $\varepsilon 4$ on cognitive impairment in non-demented subjects. Dement Geriatr Cogn Disord 2011; 32: 135-42.

35. Caselli RJ. Phenotypic differences between apolipoprotein E genetic subgroups: research and clinical implications. Alzheimers Res Ther 2012; 4: 20.

36. Jiang Q, Lee CY, Mandreka S, et al. ApoE promotes the proteolytic degradation of Abeta. Neuron 2008; 58: 681-93.

37. Bell RD, Sagare AP, Friedman AE, et al. Transport pathways for clearance of human Alzheimer's amyloid betapeptide and apolipoproteins E and J in the mouse central nervous system. J Cereb Blood Flow Metab 2007; 27: 909-18.

38. Kim J, Basak JM, Holtzman DM. The role of apolipoprotein E in Alzheimer's disease. Neuron 2009; 63: 287 303.

39. Trembath D, Ervin JF, Broom L, et al. The distribution of cerebrovascular amyloid in Alzheimer's disease varies with ApoE genotype. Acta Neuropathol 2007; 113: 23-31.

40. Morishima-Kawashima M, Oshima N, Ogata HI, et al. Effect of apolipoprotein E allele beta4 on the initial phase of amyloid beta-protein accumulation in the human brain. Am J Pathol 2000; 157: 2093-9.

41. Peck G, Smeeth L, Whittaker J, Casas JP, Hingorani A, Sharma $P$. The genetics of primary haemorrhagic stroke, subarachnoid haemorrhage and ruptal intracranial aneurysmus in adults. PLoS One 2008; 3: e3691.

42. Elias-Sonnenschein LS, Viechtbauer W, Ramakers $I H$, Verhey FR, Visser PJ. Predictive value of APOE-epsilon4 allele for progression from $\mathrm{MCl}$ to $\mathrm{AD}$-type dementia: a meta-analysis. J Neurol Neurosurg Psychiatry 2011 82: 1149-56.

43. McAsey ME, Cady C, Jackson LM, et al. Time course of response to estradiol replacement in ovariectomized mice: brain apolipoprotein E and synaptophysin transiently increase and glial fibrillary acidic protein is suppressed. Exp Neurol 2006; 197: 197-205.

44. Drzezga A, Grimmer T, Henriksen G, et al. Effect of APOE genotype on amyloid plaque load and gray matter volume in Alzheimer disease. Neurology 2009; 72: 1487-94.

45. Nathan BP, Barsukova AG, Shen F, McAsey M, Struble RG. Estrogen facilitates neurite extension via apolipoprotein $E$ in cultured adult mouse cortical neurons. Endocrinology 2004; 145: 3065-73.

46. Magierska J, Magierski R, Fendler W, Kłoszewska I, Sobów TM. Clinical application of the Polish adaptation of the Montreal Cognitive Assessment (MoCA) test in screening for cognitive impairment. Neurol Neurochir Pol 2012; 46: 130-9.

47. Gualtieri CT, Johnson LG. Reliability and validity of a computerized neurocognitive test battery, CNS VitalSigns. Arch Clin Neuropsychol 2006; 21: 623-43.

48. Yang YG, Kim JY, Park SJ, Kim SW, Jeon OH, Kim DS. Apolipoprotein $\mathrm{E}$ genotyping by multiplex tetra-primer amplification refractory mutation system PCR in single reaction tube. J Biotechnol 2007; 131: 106-10.

49. Arenaza-Urquijo EM, Gonneaud J, Fouquet M, et al. Interaction between years of education and APOE epsilon4 status on frontal and temporal metabolism. Neurology 2015; 85: 1392-9.

50. Thilers PP, Macdonald SW, Herlitz A. The association between endogenous free testosterone and cognitive performance: a population-based study in 35 to 90 year-old men and women. Psychoneuroendocrinology 2006; 31 : 565-76.

51. Ryan J, Stanczyk FZ, Dennerstein L, et al. Hormone levels and cognitive function in postmenopausal midlife women. Neurobiol Aging 2012; 33: 1138-47.

52. Davis SR, Davison SL, Gavrilescu M, et al. Effects of tes tosterone on visuospatial function and verbal fluency in postmenopausal women: results from a functional magnetic resonance imaging pilot study. Menopause 2014; 21: 410-4.

53. Raber J, Bongers G, LeFevour A, Buttini M, Mucke L. Androgens protect against apolipoprotein E4-induced cognitive deficits. J Neurosci 2002; 22: 5204-9.

54. Raber J. Androgens, apoE, and Alzheimer's disease. Sci Aging Knowledge Environ 2004; 2004: re2.

55. Pfankuch T, Rizk A, Olsen R, Poage C, Raber J. Role of circulating androgen levels in effects of apoE4 on cognitive function. Brain Res 2005; 1053: 88-96.

56. Hogervorst E, Combrinck M, Smith AD. Testosterone and gonadotropin levels in men with dementia. Neuroendocrinol Lett 2003; 24: 203-8.

57. Panizzon MS, Hauger R, Xian $\mathrm{H}$, et al. Interaction of APOE genotype and testosterone on episodic memory in middle-aged men. Neurobiol Aging 2014; 35: 1778.e1-8.

58. Rosario ER, Pike CJ. Androgen regulation of beta-amyloid protein and the risk of Alzheimer's disease. Brain Res Rev 2008; 57: 444-53.

59. Panizzon MS, Hauger R, Dale AM, et al. Testosterone modifies the effect of APOE genotype on hippocampal volume in middle-aged men. Neurology 2010; 75: 874-80.

60. Hogervorst E, Lehmann DJ, Warden DR, et al. Apolipoprotein E epsilon4 and testosterone interact in the risk of Alzheimer's disease in men. Int J Geriatr Psychiatry 2002; 17: 938-40.

61. Rizk-Jackson A, Robertson J, Raber J. Tfm-AR modulates the effects of ApoE4 on cognition. J Neurochem 2008; 105: 63-7.

62. Laughlin GA, Kritz-Silverstein D, Barrett-Connor E. Higher endogenous estrogens predict four year decline in verbal fluency in postmenopausal women: The Rancho Bernardo Study. Clin Endocrinol (Oxf) 2010; 72: 99-106.

63. Shah S, Bell RJ, Savage G, et al. Testosterone aromatization and cognition in women: a randomized, placebocontrolled trial. Menopause 2006; 13: 600-8.

64. Weill-Engerer S, David JP, Sazdovitch V, et al. Neurosteroid quantification in human brain regions: comparison between Alzheimer's and non-demented patients. J Clin Endocrinol Metab 2002; 87: 5238-42.

65. van Niekerk JK, Huppert JA, Herbert J. Salivary cortisol and DHEA: association with measures of cognition 
andwell-being in normal older men, and effects of three months of DHEA supplementation. Psychoneuroendocrinology 2001; 26: 591-612.

66. Sorwell KG, Urbanski HF. Dehydroepiandrosterone and age-related cognitive decline. Age 2010; 32: 61-7.

67. Sorwell KG, Garten J, Renner L, et al. Hormone supplementation during aging: how much and when? Rejuvenation Res 2012; 15: 128-31.

68. Marx CE, Trost WT, Shampine LJ, et al. The neurosteroid allopregnanolone is reduced in prefrontal cortex in Alzheimer's disease. Biol Psychiatry 2006; 60: 1287-94.

69. Naylor JC, Hulette CM, Steffens DC, et al. Cerebrospinal fluid dehydroepiandrosterone levels are correlated with brain dehydroepiandrosterone levels, elevated in Alzheimer's disease, and related to neuropathological disease stage. J Clin Endocrinol Metab 2008; 93: 3173-8.

70. Naylor JC, Kilts JD, Hulette CM, et al. Allopregnanolone levels are reduced in temporal cortex in patients with Alzheimer's disease compared to cognitively intact control subjects. Biochim Biophys Acta 2010; 1801: 951-9. 